\title{
INTEMPERISMO DECORRENTE DA ACUMULAÇÃO DE SAL E A FORMAÇÃO DE ALVÉOLOS E TAFONI NOS AFLORAMENTOS DAS PRAIAS DE NITERÓI (RIO DE JANEIRO, BRASIL) \\ SALT WEATHERING AND FORMATION OF HONEYCOMBS AND TAFONI ON OUTCROPS OF BEACHES IN NITERÓI (RIO DE JANEIRO, BRAZIL)
}

Maria Augusta Martins da Silva

Departamento de Geologia, Instituto de Geociências, Universidade Federal Fluminense. Av. General Milton Tavares de Souza,s $/ n, 4^{\circ}$ andar, Campus da Praia Vermelha, CEP: 24210-346, Niterói/RJ

E-mail: mariaaugustasilva0@gmail.com

José Antônio Baptista Neto

Departamento de Geologia, Instituto de Geociencias, Universidade Federal Fluminense. Av. General Milton Tavares de Souza,s $/ n, 4^{\circ}$ andar, Campus da Praia Vermelha, CEP: 24210-346, Niterói/RJ

E-mail: jabneto@id.uff.br

André Luiz Carvalho da Silva

Departamento de Geografia - FFP/Universidade do Estado do Rio de Janeiro. Rua Francisco Portela, 794, São Gonçalo/RJ.

E-mail: andrelcsilva@ig.com.br

Bernard Smith

School of Geography, Archaeology and Paleoecology, Queen's University of Belfast, Belfast BT7 1NN, Northern Ireland, UK

E-mail:b.smith@qub.ac.uk

John McAlister

School of Geography, Archaeology and Paleoecology, Queen's University of Belfast, Belfast BT7 1NN, Northern Ireland, UK E-mail:j.mcalister@qub.ac.uk

Patrícia Warke

School of Geography, Archaeology and Paleoecology, Queen's University of Belfast, Belfast BT7 1NN, Northern Ireland, UK E-mail:p.warke@qub.ac.uk

Joanne Curran

School of Geography, Archaeology and Paleoecology, Queen's University of Belfast, Belfast BT7 1NN, Northern Ireland, UK E-mail:j.curran@qub.ac.uk

Informações sobre o Artigo

Data de Recebimento:

04/08/2012

Data de Aprovação:

11/05/2013

\section{Palavras-chave:}

Intemperismo de sal; tafoni; Niterói/Brasil.

\section{Keywords:}

Salt weathering; tafoni; Niterói/ Brazil.

\section{Resumo}

Afloramentos de granitos e gnaisses nas praias de Niterói (RJ) apresentam morfologias desenvolvidas em decorrência do intemperismo da acumulação de sal na superfície da rocha. Pequenas depressões e bacias e, de modo mais organizado, morfologias denominadas alvéolos e tafoni, são frequentemente encontradas na superfície das rochas. Este trabalho apresenta uma descrição dessas morfologias com ênfase na praia de Itacoatiara onde os melhores exemplos são encontrados. Nessa praia, 12 amostras foram analisadas (MEV, IC, AAS) permitindo a identificação de halita, gipsita, silvita, bischofita, mirabilita, thenardita e kieserita. Em função dos ciclos de cristalização desses sais durante períodos de seca e posterior dissolução, ocorre a desintegração das rochas e 
formação dessas morfologias. A frequência desses ciclos promove o rompimento das ligações entre os cristais e a fadiga das rochas gerando as morfologias com aspectos cavernosos. Características geológicas, tais como, planos de esfoliação, contatos litológicos, composição e textura das rochas, entre outras, apresentam papel importante no tipo de morfologia desenvolvida durante o intemperismo de sal.

\begin{abstract}
Coastal outcrops of granites and gneisses on the beaches of Niterói (RJ) present morphologies related to salt weathering, such as pits and pans, and the more organized forms such as honeycomb and tafoni, on the surface of the rocks. This paper presents a description of these landforms on the beaches of Niterói, particularly at Itacoatiara, where better examples are found. SEM, IC and AAS analysis carried on 12 samples collected from the outcrop at Itacoatiara, identified halite, gypsum, sylvite, bischofite, mirabilite, thenardite and kieserite. Wet/dry cycles and its frequency generate salt crystalization and dissolution which promotes rock disintegration giving rise to these observed cavernous morphologies. Geological characteristics such as exfoliation planes, lithological contacts, composition and textures, among others, play an important role on the type of morphology developed during salt weathering processes.
\end{abstract}

\section{Introdução}

A ação dos sais durante o intemperismo causa mudanças nas rochas levando a formação de morfologias e partículas. Tal processo é importante especialmente em ambientes de clima árido e em ambientes costeiros e, pode ter como resultado o aparecimento de morfologias na superfície das rochas, tais como depressões, alvéolos (alguns lembram colmeias perfeitas), tafoni (BRADLEY et al, 1978; MUSTOE, 1982; GOUDIE \& VILES, 1997). Essas feições de intemperismo são comuns em todo o mundo, independente da latitude (GOUDIE \& VILES, 1997), e podem ser observadas em muitos tipos de rochas, incluindo arenitos, granitos e menos comumente em gnaisses (GOUDIE \& VILES, 1997). Os mecanismos que levam a formação dessas feições vêm sendo alvo de diversos estudos e recentemente pesquisas tem se voltado para o entendimento do papel do sal no intemperismo das rochas usadas em prédios e monumentos na tentativa de contribuir para a conservação de tais construções (IOANNOU \& THEODORIDOU, 2011).

O "stress" devido a frequente cristalização de sais na superfície das rochas, amplamente conhecido como mecanismo fundamental, é intensificado nos longos períodos de seca e consequente cristalização de sais em abundância devido a evaporação (MUSTOE, 1982; HUININK et al. 2004). Os cristais de sais promovem o rompimento físico da rocha pelo enfraquecimento das ligações entre os minerais, causando a fadiga e a desagregação das rochas com geração de partículas (posteriormente transportadas) e de morfologias. Um outro mecanismo possivelmente associado é o da ação do sal promovendo a dissolução química dos minerais ao longo de suas linhas de contato, resultando na desagregação granular e a criação das morfologias observadas (MOTTERSHEAD \& PYE, 1994; GOUDIE \& VILES, 1997). Mais recentemente foi reconhecida a importância da duração dos períodos de seca e seus resultados na intensa evaporação e cristalização abundante de sal (HUININK et al., 2004).

Este trabalho apresenta exemplos de morfologias formadas pelo intemperismo da acumulação de sal na superfície dos afloramentos rochosos das praias na cidade de Niterói (Rio de Janeiro). Esses afloramentos apresentam, frequentemente, crostas de sal e formações eflorescentes em superfície, dentro de feições alveoladas ou em depressões, sendo que as denominadas tafone podem apresentar tamanho suficiente para abrigar uma pessoa, a semelhança de uma caverna. Estes relevos são abundantes nos afloramentos das praias de Niterói, porém nunca foram reportados na literatura. O objetivo deste trabalho é o de descrever tais morfologias, apresentar os principais sais acumulados nas rochas que conduzem ao intemperismo e discutir alguns dos fatores que controlam o processo de degradação das rochas.

\section{Área de Estudo}

A cidade de Niterói tem um clima úmido tropical com temperatura média anual de $22^{\circ} \mathrm{C}$, ainda que no verão as temperaturas médias variam de $30-32^{\circ} \mathrm{C}$. A média anual de chuvas varia de 1100 a $1800 \mathrm{~mm}$, apresentando altas concentrações de aerossol marinho.

Diversas praias de Niterói, como Itacoatiara, Camboinhas, Sossego, Piratininga, Forte Barão do Rio Branco, Adão, Eva e Boa Viagem (Fig. 1) apresentam morfologias relativas aos processos relacionados ao intemperismo de sal, facilmente observadas nos afloramentos de granitos e gnaisses pré-Cambrianos. Alguns exemplos mais bem desenvolvidos podem ser vistos na Praia do Forte Barão do Rio Branco, Camboinhas e, em especial, em Itacoatiara (Figs. 2A e 3), onde belos exemplos dessas morfologias ocorrem em um afloramento de rochas graníticas, e por isso são focalizadas neste trabalho. 


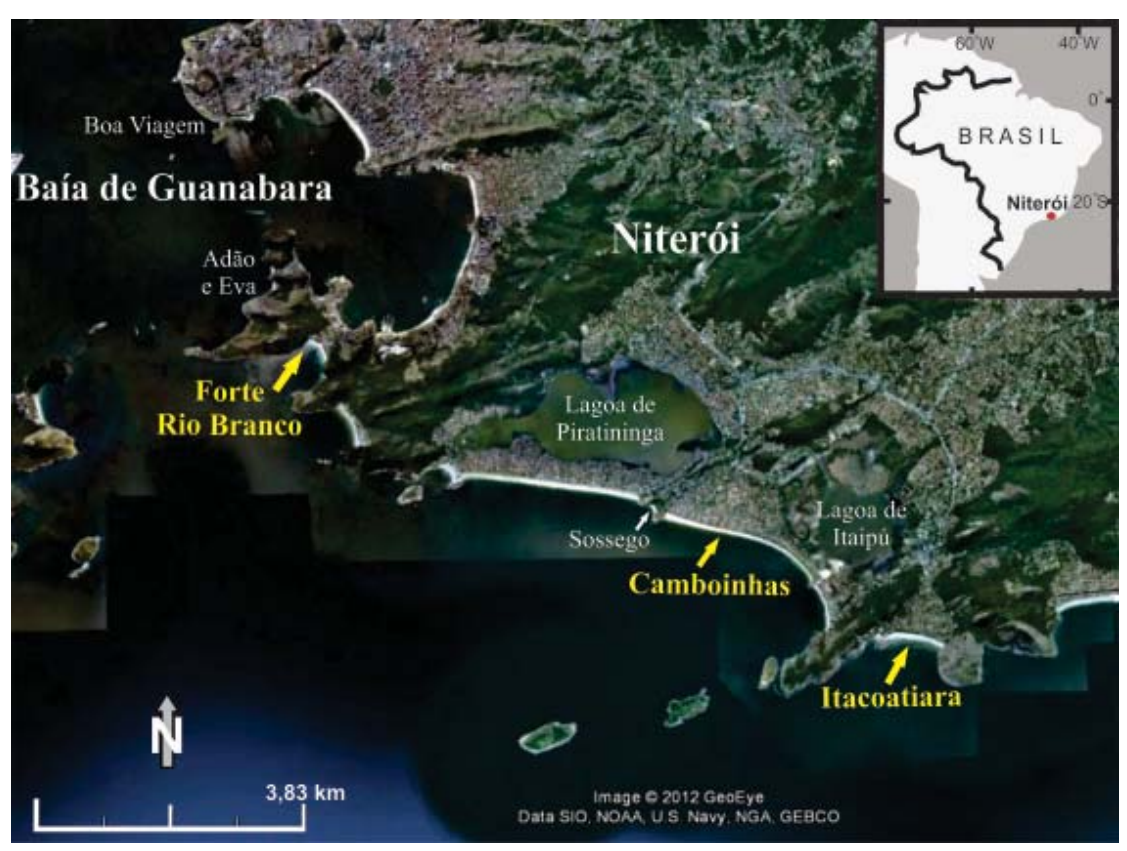

Figura 1 - Localização das praias estudadas na cidade de Niterói, estado do Rio de Janeiro. Imagem: Google Earth, 2012.

O afloramento rochoso de Itacoatiara tem cerca de 250 metros de comprimento e sua altura chega a aproximadamente 10 metros acima do nível do mar (Fig. 2A). Suas encostas apresentam declives suaves de $5^{\circ}$ a $15^{\circ}$, mas são íngremes nas faces voltadas para o mar. A variação da maré ao longo desta costa é menor do que 1,5 metro. As faces do afloramento voltadas para o mar, normalmente recebendo ondas de $1 \mathrm{a}$ 2 metros de altura na arrebentação, são mais intensamente afetadas por ondas durante as ressacas, que podem, até mesmo cobrir todo o afloramento rochoso alcançando o lado inter- no do costão esporadicamente. A água do mar, bem como a umidade presente na atmosfera e o spray marinho, além da água das chuvas, se acumulam nas depressões e criam pequenas bacias preenchidas com água salgada que, com o tempo se tornam salmouras, devido à intensa e prevalecente evaporação durante os meses mais secos do ano. Eventualmente esta salmoura pode secar quase que completamente e como resultado depósitos de sal e crostas eflorescentes são observados na superfície das rochas, nas depressões, bem como, nas fraturas, e outros locais (Fig. 4).

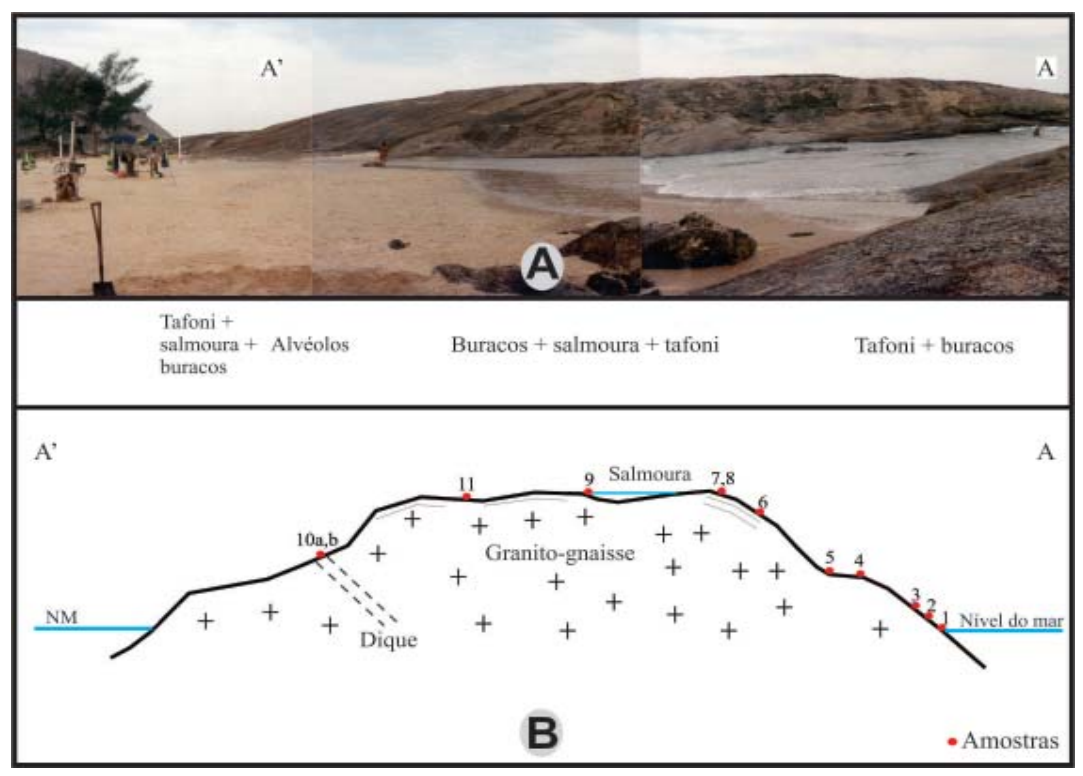

Figura 2 - Afloramento de granito na praia de Itacoatiara (A); (B) esquema representando o afloramento com locais de coleta de amostras, $e$ distribuição das principais morfologias. $O$ afloramento tem cerca de 250 metros de comprimento e aproximadamente 10 metros de altura. 

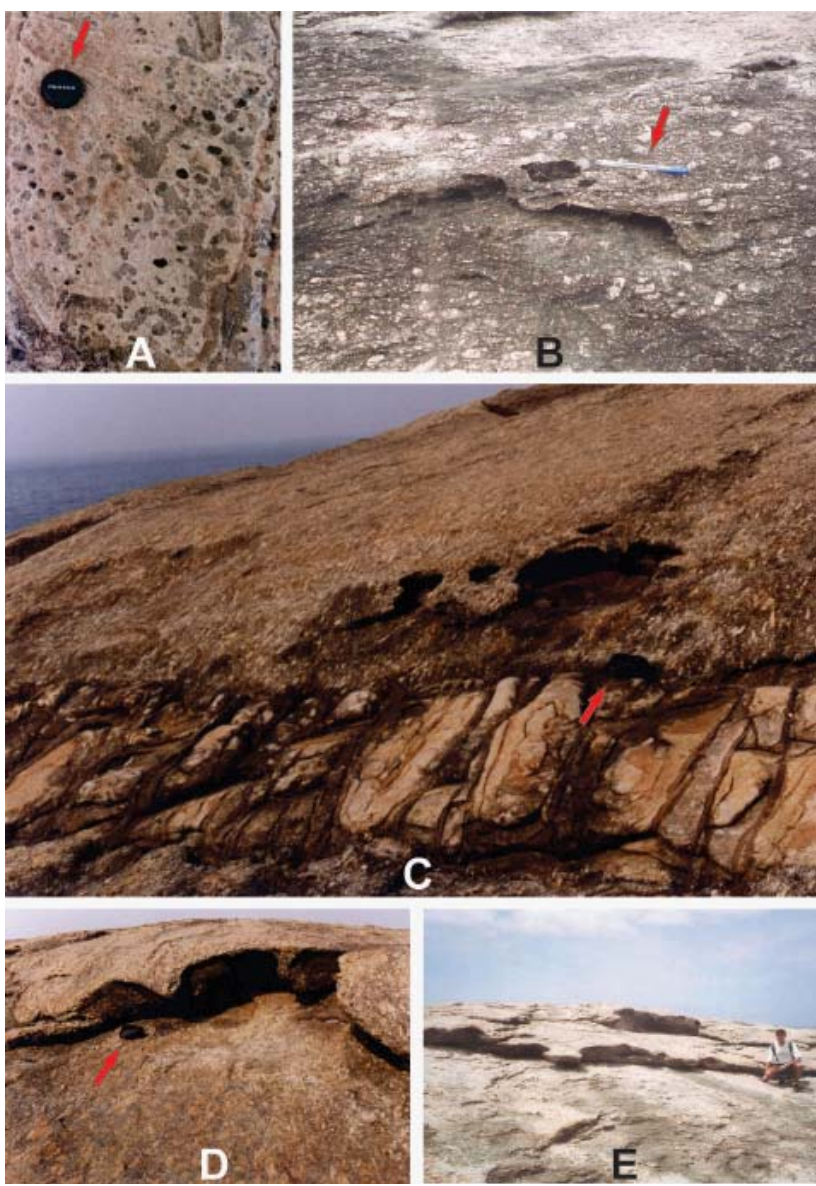

Figura 3 - Praia de Itacoatiara: alvéolos em estágio incipiente de formação em dique de textura fina (seta aponta tampa de máquina fotográfica) (A); tafone pequeno (escala - caneta) (B); tafone exibindo telhado no contato entre granito e dique (C) (escala - capa da máquina fotográfica); tafone bem desenvolvido formado ao longo de plano de esfoliação da rocha (escala- capa da máquina fotográfica) (D); tafoni em diferentes estágios de formação ao longo de planos de esfoliação (E).
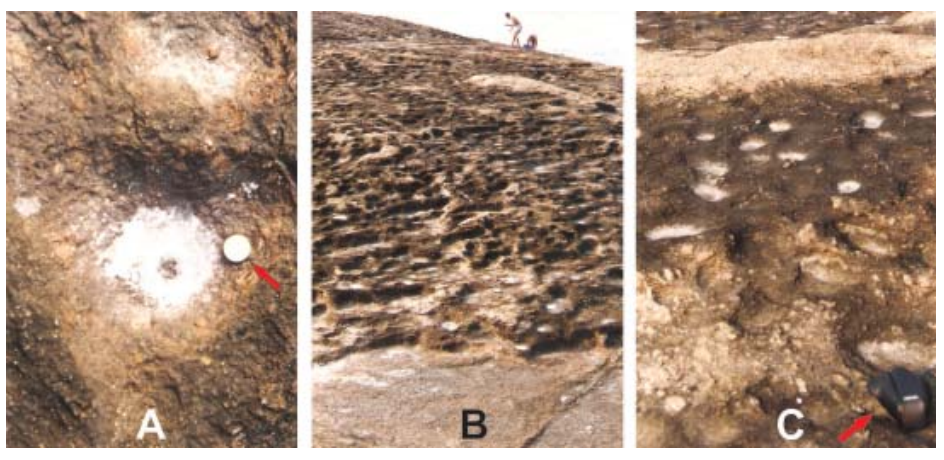

Figura 4 -Depressões e pequenas bacias preenchidas com sal na superficie da rocha na praia de Itacoatiara. Escalas: seta aponta moeda em A e capa da máquina fotográfica em $C$.

\section{Metodologia}

Ao longo de um perfil, realizado desde a marca da maré alta, passando pelo topo do afloramento, até a extremidade oposta do mesmo (Fig. 2B), 12 amostras foram coletadas com a proposta de um reconhecimento da presença dos sais e suas possíveis variedades. A amostragem foi feita com o auxílio de uma furadeira de alto impacto modelo Hilti -TE76 que retira um pequeno testemunho de 10 a 15 centímetros de espessura da rocha. Algumas amostras foram coletadas manualmente com auxílio de um martelo. O material coletado, na forma de 12 pequenos fragmentos de rocha intemperizada, e montados em placas de alumínio cobertos por uma película de ouro, foi analisado em um microscópio eletrônico de varredura (MEV) (da marca Joel Winsen JSM 6400, pertencente a Queen's University em Belfast, Irlanda do Norte). A partir da fração de tamanho menor que $63 \mu \mathrm{m}$, sais solúveis em água foram extraídos agitando-se 2 gramas de amostra em $10 \mathrm{ml}$ de água deionizada por duas horas, e deixando descansar por uma noite a temperatura ambiente antes da centrifugação e posterior filtragem através de filtros de $0.2 \mu \mathrm{m}$ de membrana. Os cátions $\mathrm{Na}, \mathrm{K}, \mathrm{Mg}, \mathrm{Ca}, \mathrm{Cr}, \mathrm{Mn}, \mathrm{Fe}, \mathrm{Ni}, \mathrm{Cu}, \mathrm{Pb}$ e $\mathrm{Zn}$ foram analisados usando-se um espectrômetro atômico de absorção Perking Elmer modelo 3100. Uma chama de ar/acetileno foi empregada para atomizar as soluções. Íons solúveis em água foram extraídos pela técnica de extração de $0.5 \mathrm{gm}$ da amostra em $2.5 \mathrm{~cm}^{3}$ da água deionizada e filtrada pela membrana de $0.2 \mu \mathrm{m}$. Os extratos foram também filtrados através da membrana de $0.2 \mu \mathrm{m}$ antes da analise de IC. Os ânions solúveis em água, $\mathrm{F}, \mathrm{Cl}, \mathrm{NO}_{3}$, $\mathrm{PO}_{4}$ e $\mathrm{SO}_{4}$, foram analisados usando-se um íon cromatógrafo Dionex Model DX 500. Análises mineralógicas do material intemperizado foram realizadas em um difratômetro de Raio-X Siemens D5000. A petrografia do granito foi realizada em um microscópio petrográfico da marca Nikon.

\section{Resultados e discussão}

O afloramento em Itacoatiara é formado por rochas cuja composição apresenta abundantes cristais de quartzo, feldspatos (microclina e albita, principalmente), biotita e granada. Quantidade menor de ilita está presente (SMITH et al., 2004). Pegmatitos e veios ricos em cristais de feldspatos, micas e quartzo, bem como diques compostos por rocha de composição granítica de textura fina são também comuns no afloramento estudado. Além disso, diques de diabásio do Cretáceo são comuns e cortam as rochas regionais.

Altas concentrações de $\mathrm{Na}, \mathrm{K}, \mathrm{Ca}, \mathrm{Mg}, \mathrm{Cl}$ e $\mathrm{SO}_{4}$ foram encontradas nas amostras (Tabela 1). Existe uma correlação entre os elementos $\mathrm{Na}$ e $\mathrm{Cl}, \mathrm{K}$ e $\mathrm{Cl}$ e também entre o $\mathrm{Mg}$ e Cl (Tabela 2) demonstrando a presença importante de cloretos, tais como halita, silvinita e bischofita. Existe também uma correlação entre $\mathrm{Ca}, \mathrm{Mg}$ e $\mathrm{SO}_{4}$, e mais sutilmente, entre $\mathrm{Na}$ e $\mathrm{SO}_{4}$, o que indica a presença de diversos sulfatos, como gipsita, mirabolita, thenardita e kieserita. Analises realizadas no MEV confirmaram a presença de cristais de gipsita $\left(\mathrm{CaSO}_{4} \cdot 2 \mathrm{H}_{2} \mathrm{O}\right)$ e halita $(\mathrm{NaCl})$ (Fig. $5 \mathrm{~A} \mathrm{e} \mathrm{B}$, respectivamente). Esses sais são encontrados em diversas partes do mundo formando crostas e eflorescências (GOUDIE \& VILES, 1997). 
A presença de silvita $(\mathrm{KCl})$ indica taxas altas de evaporação alcançando níveis de total dissecação do corpo d'água. De modo geral, a fonte desses elementos é o mar, porém, devido ao clima úmido e quente da região o intemperismo químico de feldspatos e micas libera também alguns desses elementos para a formação dos sais encontrados no afloramento.

Tabela 1 - Resultados da cromatografia de íons para as amostras de Itacoatiara (todos os resultados expressos como percentagem de concentração de peso).

\begin{tabular}{|c|c|c|c|c|c|c|c|c|}
\hline AMOSTRAS & $\mathrm{Na}$ & $\mathbf{K}$ & Ca & $\mathbf{M g}$ & $\mathbf{F}$ & $\mathrm{Cl}$ & $\mathrm{SO}_{4}$ & $\mathrm{NO}_{3}$ \\
\hline $\begin{array}{l}1 \text { (nível do } \\
\text { mar) }\end{array}$ & 347 & 111 & 58 & 25 & 7.98 & 432 & 113 & 0 \\
\hline $\begin{array}{l}2 \text { (nível do } \\
\text { mar) }\end{array}$ & 323 & 127 & 49 & 25 & 6.7 & 516 & 100 & 0 \\
\hline $\begin{array}{l}3 \text { (topo zona } \\
\text { de algas) }\end{array}$ & 558 & 157 & 54 & 57 & 7.2 & 879 & 198 & 0 \\
\hline $\begin{array}{l}\text { 4(acima zona } \\
\text { de algas) }\end{array}$ & 425 & 129 & 90 & 67 & 6.6 & 621 & 381 & 0 \\
\hline 5 (bacias) & 883 & 195 & 709 & 167 & 8.5 & 1805 & 2053 & 0 \\
\hline 6 (bacias) & 8423 & 3495 & 587 & 933 & 0 & 12252 & 2314 & 0 \\
\hline $\begin{array}{l}7 \text { (dentro } \\
\text { tafoni) }\end{array}$ & 232 & 422 & 4 & 7 & 4 & 326 & 57 & 0 \\
\hline $\begin{array}{l}8 \text { (topo } \\
\text { tafoni) }\end{array}$ & 249 & 82 & 5 & 16 & 0.8 & 366 & 82 & 0 \\
\hline $\begin{array}{l}9 \text { (bacia topo } \\
\text { afloramento) }\end{array}$ & 637 & 219 & 1724 & 165 & 0 & 1027 & 2296 & 0 \\
\hline 10a (dique) & 336 & 152 & 812 & 33 & 0.5 & 555 & 91 & 29 \\
\hline $10 b$ (dique) & 366 & 77 & 19 & 38 & 3.9 & 641 & 69 & 0 \\
\hline $\begin{array}{l}11 \text { (topo } \\
\text { afloramento) }\end{array}$ & 122 & 84 & 40 & 8 & 1.4 & 150 & 65 & 0 \\
\hline
\end{tabular}

Tabela 2 - Correlação entre elementos maiores baseada nos resultados de IC e AAS.

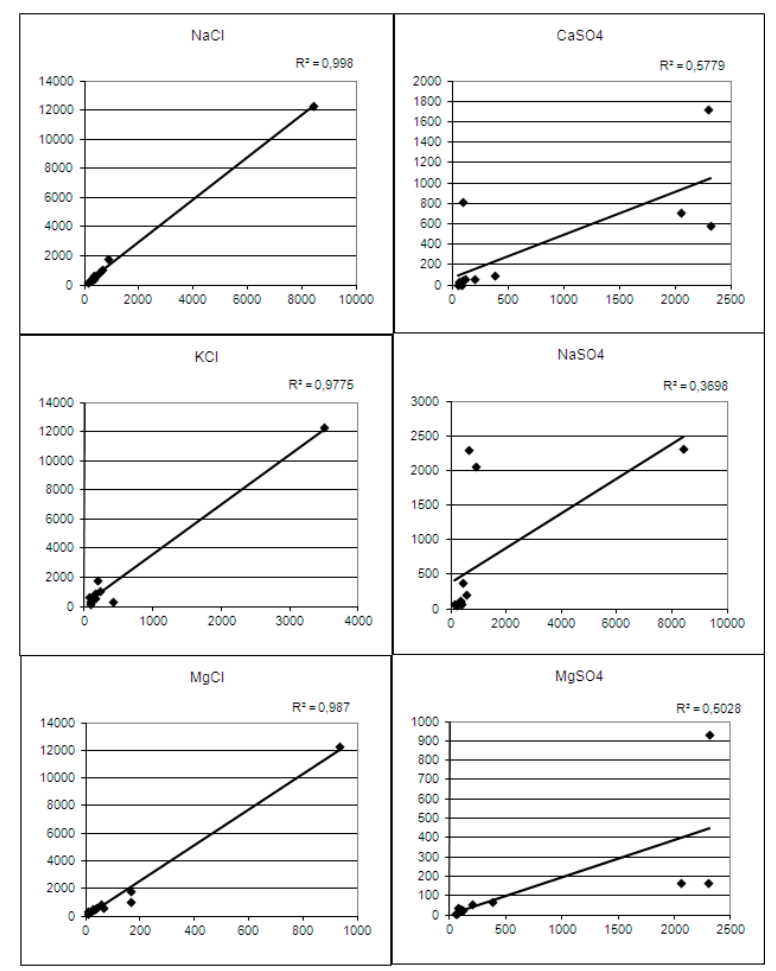

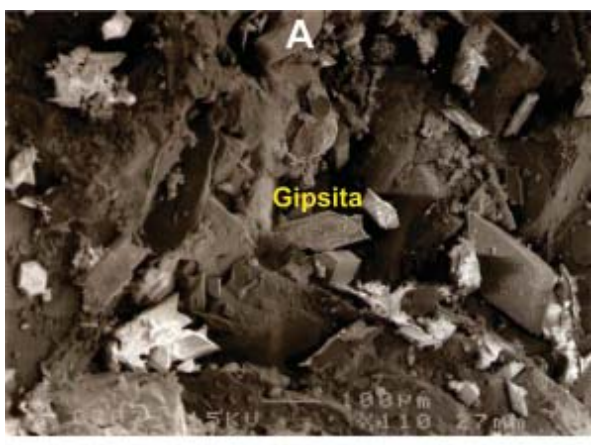

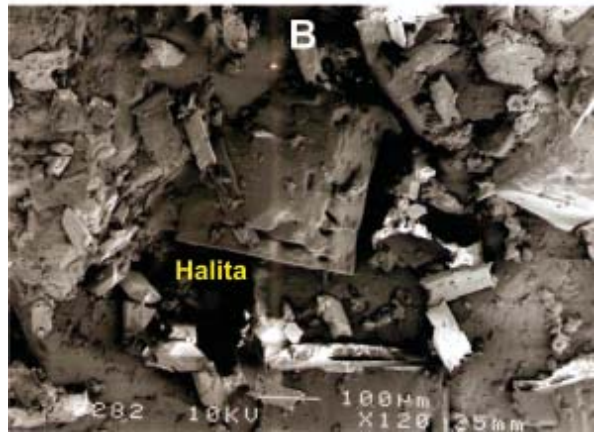

Figura 5-Fotos tiradas no microscópio eletrônico de varredura mostrando gipsita (A) e halita (B). (Escala-barra corresponde a 1007m).

O processo cíclico de cristalização de sais a partir de uma solução rica em sais, posterior dissolução e recristalização é considerado a causa para o rompimento e desagregação da rocha devido a fadiga, levando a desintegração granular que pode ser vista como acúmulo de partículas de tamanhos areia e silte na superfície da rocha, bem como a formação das morfologias aqui estudadas. Essas morfologias aparecem sob diferentes tamanhos começando como feições pequenas (milimétricas), como depressões, distribuídos de forma aleatória na superfície da rocha (Figs. 3A; 4A, B e C; 6C) ou de forma organizada lembrando muito uma casa de abelha, denominada de alvéolo (Fig. 6B); de tamanho maior (centímetros a poucos metros), o tafone pode chegar as dimensões de uma pequena caverna, no sentido de poder abrigar uma pessoa (Figs. 3B, C, D e E; 7B e C).

Intemperismo e erosão dos minerais menos resistentes, como biotita, promovem a formação de pequenas depressões na superfície da rocha, separadas entre si por micro relevos positivos formados por grandes cristais de feldspatos (Fig. 6C). Características geológicas tais como composição, textura, planos de esfoliação e contatos litológicos parecem controlar o tipo de morfologia resultante do intemperismo de sal. Rochas com composição mais homogênea (como bandas ricas em biotita, concentrações de ferro em crostas) e/ou texturas finas tendem a desenvolver alvéolos (Fig. 6B). Tafone ocorre por todo o afloramento em Itacoatiara (Figs. 3B, C, D e E). Alguns apresentam 1 metro ou mais de altura e profundidade, apresentando um telhado (um bom exemplo pode ser visto na Fig. 3D), de modo que uma pessoa sentada cabe dentro dessa feição que lembra uma pequena caverna, enquanto outros estão ainda em estado inicial de desenvolvimento (Fig. 3B). 
Contatos litológicos, planos de fraturas (Figs. 3C; 7B e C), bem como, planos de esfoliação (Fig. 3E), são locais ideais para o início de formação do tafone. Isso ocorre por que não só as soluções ricas em sais podem penetrar mais na rocha, mas também porque a umidade rica em sais pode penetrar ainda mais e ficar retida por mais tempo no interior desses planos de fraqueza da rocha. Isto parece ocasionar, a partir da lenta evaporação dessa umidade, a nucleação de cristais ainda maiores, o que acelera o intemperismo. Aumento do teor de umidade carregado de sais provoca a deliquescência dos cristais anteriormente formados e, posteriormente, cristais ainda maiores e puros são formados causando a desagregação mais rápida da rocha (DESARNAUD et al., 2011). Os ciclos de umidade e de evaporação vem sendo considerados como fatores ainda mais importantes para o intemperismo de sal (HUININK et al., 2004; DESARNAUD et al., 2011). Estudos recentes vem focalizando no entendimento do papel da umidade após períodos prolongados de chuvas ou outras entradas de água no sistema, como a causa mais importante para o transporte de sais para porções mais interiores das rochas, o que promove a ação intempérica a níveis mais profundos. Isso no caso de construções e monumentos tem implicações sérias para a degradação dessas estruturas (MCALLISTER et al., 2011; MCCABE et al., 2011).

\section{Conclusões}

Afloramentos de granitos e gnaisses nas praias de Camboinhas, Forte do Rio Branco e, em especial, em Itacoatiara (Niterói/RJ) apresentam em superfície, morfologias resultantes do intemperismo devido ao acúmulo de sal, tais como, depressões, bacias, alvéolos e tafoni. Em Itacoatiara, onde os melhores exemplos podem ser vistos, doze amostras foram coletadas e analisadas (MEV, DRX, IC e AAS) e os resultados indicaram a existência de vários sais de cloretos e sulfatos: halita, gipsita, silvita, bischofita, mirabilita, thenardita e kieserita. Estes sais podem ser vistos como eflorescências, como crostas e depósitos preenchendo as fissuras das rochas, bem como em depressões e bacias após períodos prolongados de seca. A natureza cíclica da cristalização dos sais e posterior dissolução, bem como a frequência de ocorrência desses ciclos, parece ser o fator mais importante para os processos de intemperismo de sal e a formação de feições cavernosas, observadas nos afloramentos. A pressão de cristalização dos sais provoca a fadiga das rochas por promover o rompimento das ligações entre os cristais, causando com o tempo a desintegração das rochas. $\mathrm{O}$ desenvolvimento das morfologias é ainda mais acentuado pelo contínuo e cíclico processo de precipitação de sais e dissolução, bem como pela deliquescência, em função de ciclos de umidade alternando com períodos de evaporação.

Algumas características geológicas favorecem o processo e o tipo de morfologia resultante, como a compo- sição mais homogênea da rocha, textura mais fina, zonas de fraqueza como planos de esfoliação e contatos litológicos. Zonas ricas em biotita, bem como concentrações de ferro na superfície das rochas, controlam a formação de alvéolos; a formação de alvéolos é também facilitada pela textura fina das rochas, como no caso de alguns diques. Em locais onde há abundância de feldspatos grossos, depressões são formadas e se distribuem aleatoriamente criando uma superfície caracterizada por cristais protuberantes de feldspatos. Os planos de esfoliação e juntas de alívio, tão característicos dos afloramentos estudados, são locais ideais para o desenvolvimento dos tafoni e dão origem a formas de relevo bastante interessantes.
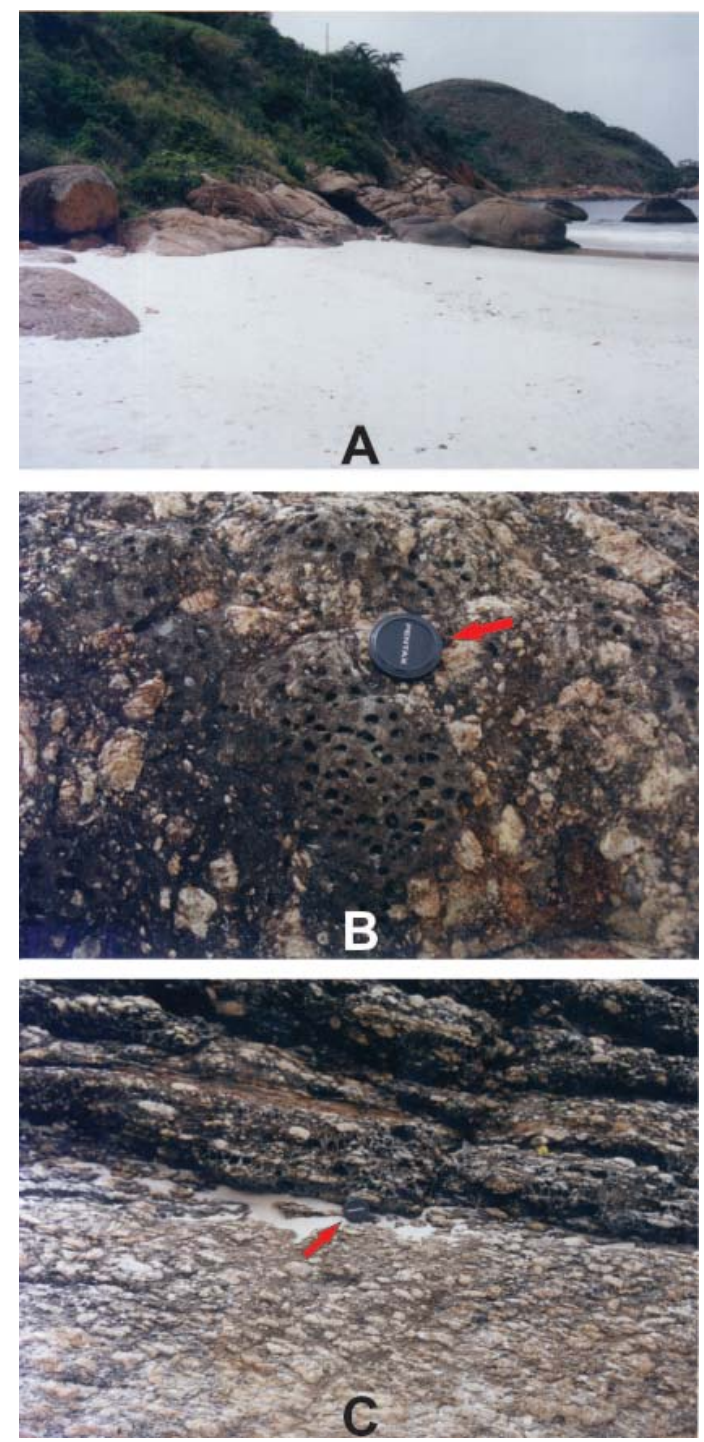

Figura 6-Afloramento na praia do Forte Barão do Rio Branco (A); detalhe do afloramento de gnaisse mostrando alvéolo em crosta de ferro (B); depressões formadas preferencialmente em banda rica em biotita no gnaisse (C). Seta indica tampa de máquina fotográfica usada como escala. 


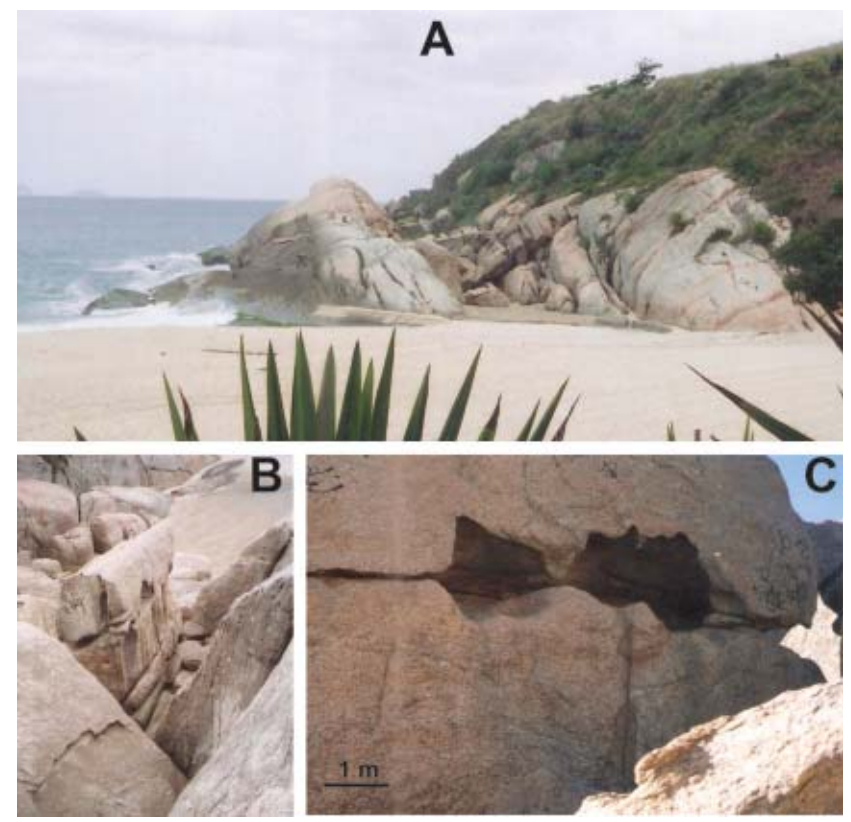

Figura 7 - Afloramento de gnaisse na praia de Camboinhas (A); detalhes de tafoni $(B$ e $C)$.

\section{Agradecimentos}

Agradecemos a CAPES, a FAPERJ e ao British Council pelo apoio financeiro. Ao CNPq e a FAPERJ pelas bolsas de estudos aos estudantes de iniciação científica. Gostaríamos de agradecer também ao Departamento de Geologia da Universidade Federal Fluminense (UFF) e a School of Geography, Archaeology and Paleoecology da Queen's University de Belfast, na Irlanda do Norte. Somos muito gratos a todos os estudantes que participaram dos trabalhos de campo, em especial a Carla Luiza dos Santos, George Uller e Cristiane Ferreira da Silva. A todos, colegas, funcionários e estudantes, nossos sinceros agradecimentos.

\section{Referências bibliográficas}

BRADLEY, W. C., HUTTON, J. T. AND TWIDALE, C. R. Role of salts in development of granitic tafoni, South Australia. Journal of Geology, 86, 647-654. 1978.

DESARNAUD, J., BERTRAND, F. \& SHAHIDZADEHBONN, N. Dynamics of salt crystallization. In: Ioannou \& Theodoridou (eds.) SWBSS, Chipre, 23-30. 2011.

GOUDIE, A. \& VILES, H. Salt Weathering Hazards. John Wiley \& Sons, pp. 241. 1997.

HUININK, H. P., PEL, L. \& KOPINGA, K. Simulating The Growth Of Tafoni. Earth Surface Processes and Landforms, 29, 1225-1233. 2004.

IOANNOU, I. \& THEODORIDOU, M. (eds.). Salt Weathering on Buildings and Stone Sculptures. SWBSS, Chipre, pp. 427. 2011.

MCALLISTER, D., MCCABE, S., SRINIVASAN, S., SMITH, B. J. \& WARKE, P.A. Moisture dynamics in building sandstone: implications for transport and accumulation of salts. In: Ioannou \& Theodoridou (eds.). SWBSS, Chipre, 39-46. 2011.

MCCABE, S., SMITH, B. J., MCALISTER, J. J., MCALLISTER, D. SRINIVASAN, S., BASHEER, P. A. M. \& CURRAN, J. $M$. Linking climate change, moisture dynamics and salt movement within natural building sandstones: implication for salt transport by diffusion. In: Ioannou \& Theodoridou (eds.). SWBSS, Chipre, 63-70. 2011.

MOTTERSHEAD, D. N. \& PYE, K. Tafoni on Coastal Slopes, South Devon, UK. Earth Surface Processes and Landforms, 19, 543-563. 1994.

MUSTOE, G. E. The origin of honeycomb weathering. Geological Society of America Bull, 93, 108-115. 1982.

SMITH, B. J., BAPTISTA NETO, J. A., SILVA, M. A. M., MCALISTER , J. J., WARKE, P. A. \& CURRAN, J. M. The decay of coastal forts in southeast Brazil and its implications for the conservation of colonial built heritage. Environmental Geology, 46, 493-503. 2004. 